\title{
UMA TRADUÇÃO COLETIVA DAS METAMORFOSES 10.1-297 COM VERSOS HEXAMÉTRICOS DE CARlos Alberto NunEs
}

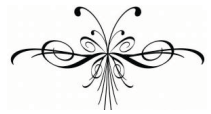 \\ RODRIGO TADEU GONÇALVES (COORDENADOR) ${ }^{1}$ ET ALII
}

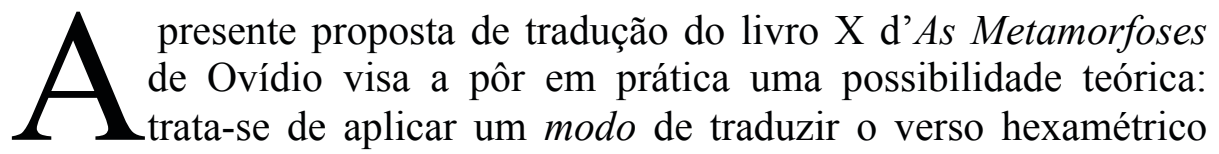
greco-latino por um verso vernáculo que, embora baseado na intensidade, isto é, na tonicidade e na atonicidade das sílabas, espelhasse a estrutura do hexâmetro, que era baseado na quantidade, isto é, na longura e na brevidade das sílabas. Trata-se de proposta peculiar sob vários aspectos, a começar pelo fato de ter sido levada a cabo não por um, nem mesmo dois tradutores, mas por um grupo cujo tamanho variou ao longo do tempo e hoje conta com nada menos do que dez pessoas, entre colaboradores e tradutores ${ }^{2}$.

Uma decorrência do tamanho do grupo é que tivemos de pôr em acordo concepções muito divergentes de tradução, de literatura e do que deveria ser nossa tarefa. Assim, no início não era claro, como agora, que a proposta de trabalho era antes de tudo aplicar um modo de traduzir certo tipo de verso. No começo do grupo, os membros foram convocados pelo professor Rodrigo Tadeu Gonçalves durante duas disciplinas da graduação em Letras da UFPR, no segundo semestre de 2007 e no primeiro de 2008, quando se discutiu que verso deveríamos escolher para a tradução, que logo percebeu-se ser mera formalidade, pois a concepção original do grupo como inicialmente concebida por Gonçalves já incluía o metro a ser utilizado. A própria escolha do texto a traduzir mostrou-se ainda mais pacífica do que a opção pelo verso: discutimos algumas possibilidades, mas acabamos por optar pelas Metamorfoses de Ovídio,

\footnotetext{
${ }^{1}$ Autores: Rodrigo Tadeu Gonçalves (coordenador), Álvaro Kasuaki Fujihara, Gabriel Dória Rachwal, Leandro Dorval Cardoso, Livy Maria Real Coelho, Luana de Conto, Marina Chiara Legroski.

Equipe de tradução: Álvaro Kasuaki Fujihara, Elias dos Santos Paraizo Jr., Gabriel Dória Rachwal, Leandro Dorval Cardoso, Livy Maria Real Coelho, Luana de Conto, Marianna Sella, Marina Chiara Legroski, Rodrigo Tadeu Gonçalves; Lorena Pantaleão, Luciana Kimi Iwamoto.

${ }^{2}$ Gostaríamos de agradecer imensamente a leitura criteriosa e os inúmeros comentários e sugestões do professor João Angelo Oliva Neto, auxílio inestimável tanto com relação ao estilo do texto da introdução, quanto com soluções mais eficientes em diversas passagens da tradução poética.
} 
que não têm ainda tradução poética integral para o português, mas só traduções parciais de Bocage, Antônio Feliciano de Castilho e Francisco José Freire (Cândido Lusitano; ver referências bibliográficas), e atualmente estão sendo traduzidas em versos dodecassilábicos pelo professor Raimundo Carvalho, da UFES.

A escolha, é claro, não foi gratuita. Embora presumivelmente quem votou a favor do texto ovidiano tivesse suas razões particulares para fazê-lo, nas discussões algumas boas razões foram apresentadas, a principal das quais reside na peculiaridade do texto e na sua inclusão no gênero épico. A estrutura do carmen perpetuum ovidiano, que consiste de uma teia de mitos entrelaçados em uma cadeia narrativa, muito pouco lembra a épica heróica de Virgílio ou de Homero (Toohey, 1992). Contudo, como aponta Anderson (apud Boyle, 1997), há uma tensão bem marcada entre épica e elegia, que faz do poema uma espécie de híbrido, de modo que o metro, sozinho, não pode ser considerado razão suficiente para chamar épico o poema ovidiano. Apesar disso, parece claro que é justamente a escolha de um metro marcadamente épico para narrar os episódios não raro amorosos das Metamorfoses que põe em jogo a tensão entre épico e elegíaco no poema.

Assim, a escolha do metro em nossa tradução ocupa lugar proeminente e lhe daremos especial ênfase nos comentários a seguir, o que não significa que deixaremos de lado a relevante questão da poeticidade do texto final. O metro escolhido alinha-se ainda com uma proposta geral de trabalho, segundo a qual o texto traduzido considere o texto de partida, enfatizando suas características, aspectos linguísticos, estilísticos, mesmo que em detrimento da adequação do produto final ao sistema linguístico e literário do português. Partimos, é claro, da tradicional discriminação de Schleiermacher ([1813] 2001) entre a estratégia tradutória que procura aproximar o autor do leitor e aquela que procura percorrer o caminho inverso, como discutiremos adiante. Nossa estratégia, portanto, procura dar a conhecer ao leitor o estranho, o texto ovidiano marcado como texto produzido em outra cultura e outra época. Contudo, procuramos também sempre manter em nosso horizonte que nossa tradução deve, antes de mais nada, ser um poema em português, ainda que nossas escolhas por vezes se afastem das convenções literárias estabelecidas pela tradição poética em língua portuguesa.

Procuramos, sobretudo, adotar postura prática coerente com os objetivos estabelecidos em nosso projeto de tradução. Entendemos, pois, que a opção por traduzir o metro latino por uma forma não consagrada em português seja perfeitamente justificável em vista da estratégia tradutória adotada que visa aproximar o leitor do autor. Nos comentários que se seguem, procuraremos justificar nossas opções, e então não só poderemos, como deveremos ser cobrados pela coerência alegada. 


\section{A tradição iniciada por Carlos Alberto Nunes, tradutor dos clássicos}

Ao traduzir seguimos o modelo da tradução poética feita por Carlos Alberto Nunes, que verteu os poemas épicos de Homero - Ilíada e Odisséia - e de Virgílio - a Eneida - transpondo hexâmetro datílico antigo por um hexâmetro datílico equivalente português.

A fórmula métrica utilizada por Carlos Alberto Nunes é motivo de muita divergência entre estudiosos e admiradores. A causa reside basicamente no fato de que o padrão acentual da língua portuguesa não coincide com o sistema fonológico latino, e assim não acomodaria o esquema métrico baseado na duração vocálica - longa ou breve - usado na antiga produção poética grecoromana (adiante discutiremos especificamente esse ponto na seção "Problemas e Soluções").

As questões que estimularam o tradutor a optar por esse esquema métrico justificam sua decisão inovadora. Nunes almejava, sobretudo, aproximar o leitor do ritmo clássico, o ritmo do hexâmetro datílico, que era, por assim dizer, a marca do gênero épico. Não sem razão, Ênio, diferentemente de Lívio Andronico ao traduzir em versos satúrnios a Odisseia, já fizera a mesma escolha, por saber que o hexâmetro datílico convinha à epopeia, como já haviam prescrito Aristóteles ${ }^{3}$ e depois prescreveria Horácio ${ }^{4}$.

Levando em consideração que Carlos Alberto Nunes chegou até mesmo a compor uma epopeia nacional intitulada Os Brasileidas (1962), é possível compreender a importância que ele mesmo dedicava ao gênero épico. Como introdução ao poema, publicou o "Ensaio sobre a Poesia Épica", em que se revela apaixonado pelo epos. Passo a passo, Nunes procura ali mostrar os elementos que teceriam uma epopeia nacional brasileira e referenda que "o assunto impõe o gênero" (p. 15). Revela-se, assim, grande conhecedor dos mecanismos que integram os poemas épicos e, por isso, não ingenuamente procura adaptar o verso helênico às possibilidades da língua portuguesa ${ }^{5}$.

Assim, a recusa do metro camoniano não foi gratuita. Em oposição ao seu principal predecessor na empresa de traduzir as epopeias de Homero e de Virgílio, Manoel Odorico Mendes, Nunes, ao adotar um hexâmetro português, optou por enfatizar a estranheza exatamente como vemos em Pannwitz (apud Benjamin, 2001: 211):

\footnotetext{
${ }^{3}$ Poética, XXIV, 1459b, 32.

${ }^{4}$ Arte Poética, 73-74.

${ }^{5}$ Deve-se atentar para o fato de que Nunes ao compor usa decassílabo, mas ao traduzir usa hexâmetro vernáculo. Nunes parece, ao compor em português, saber que se integra à tradição camoniana, e ao traduzir do latim e do grego traz o estranho ao português. A questão transferese para a razão pela qual Nunes emula diretamente Camões ao usar o decassílabo, e não Homero, como poderia fazer se usasse o próprio metro que ele mesmo introduziu em português, o hexâmetro. Nunes endossa a emulação e imitação no ato de compor, o que pressupõe eleger modelos, e a eleição de Camões para contar feitos de um povo muito tributário do povo português, segundo a visão mítica que adota no poema, responde à conveniência, tomada como decoro e utilidade, de emular com aquele que maiormente cantou façanhas lusitanas, que foi Camões nos Lusíadas. Tudo isso é patente no próprio título do poema, Brasileidas, que não encarece uma cidade, Ílion, nem um herói, Odisseu, Enéias, mas um povo, os brasileiros, justamente como fizera Camões.
} 


\begin{abstract}
Nossas traduções (mesmo as melhores) partem de um falso princípio, elas querem germanizar o sânscrito, o grego, o inglês, ao invés de sanscritizar, grecizar, anglicizar o alemão. Elas possuem um respeito muito maior diante dos próprios usos linguísticos do que diante do espírito da obra estrangeira... O erro fundamental de quem traduz é apegar-se ao estado fortuito da própria língua, ao invés de deixar-se abalar violentamente pela língua estrangeira. Sobretudo quando traduz de uma língua muito distante, ele deve remontar aos elementos últimos da própria língua, onde palavra, imagem e som se tornam um só; ele tem de ampliar e aprofundar sua língua por meio do elemento estrangeiro; não se tem ideia em que medida isso é possível, até que ponto cada língua pode se transformar, e uma língua se diferencia de outra quase que só como um dialeto de outro dialeto, e não são tomadas de modo demasiado leviano, mas precisamente quando tomadas em todo o seu peso.
\end{abstract}

No hexâmetro vernáculo de Nunes, as sílabas tônicas correspondem às sílabas longas que obrigatoriamente iniciavam o pé dátilo no grego e no latim, e as átonas correspondem às sílabas breves que o sucediam. Na verdade, Nunes por meio da tonicidade (ou intensidade), manteve os ictos que incidiam na primeira sílaba, sempre longa, de cada pé dátilo (ou, como se verá, do espondeu que o substituía): "icto" é o termo pelo qual metricistas antigos e metricistas modernos que tratam de poesia clássica denominam as sílabas tônicas. Entretanto, a tarefa teve obstáculos, pois, ainda que o português possua a tonicidade semelhante à que existia em grego e latim, não possui, porém, quantidade, isto é, a duração longa ou breve das vogais desses os idiomas: esta é a questão mais relevante, origem de toda nossa discussão. Ora, a partir da intensidade das vogais (tônicas ou átonas) é que se estabeleceram esquemas métricos do português, pautados no número de sílabas tônicas e na posição delas no verso, ao passo que no esquema quantitativo do grego e do latim, e até do inglês e alemão, o verso, grosso modo, é constituído por determinado número de células métricas, denominados "pés", formados por sua vez pela combinação de sílabas longas e breves. No esquema quantitativo, que se dá no tempo, uma vogal longa dura aproximadamente o dobro de uma vogal breve. Por consequência, duas sílabas breves podiam ser substituídas por uma sílaba longa, ou vice-versa, sem que se alterasse a duração total do verso, ainda que fosse alterado o número de sílabas. Assim, a possibilidade de substituir o dátilo por espondeu, decorrente da equivalência temporal entre duas sílabas breves e uma longa, não é possível no hexâmetro português, porque acarretaria sequência de mais de duas sílabas tônicas, que prejudica o ritmo poético almejado. Em outras palavras, o encontro no grego e no latim de um espondeu com o início do pé seguinte, que - seja dátilo, seja espondeu - será sempre iniciado por sílaba longa, provoca na transposição ao português uma sequência de três sílabas tônicas, algo como Estes botões são mágicos. Seqüências como essa são raras em nossa língua e na verdade tão estranhas à índole do idioma, que acabam por desfazer-se, não sendo mais o encontro de três tônicas, já que automaticamente a tonicidade da sílaba medial, "são", passa a ter menor intensidade que a das sílabas adjacentes.

Desse obstáculo decorre outro: a menor possibilidade de variação rítmica em cada hexâmetro vernáculo: enquanto o hexâmetro antigo, por causa daquela possibilidade de substituição, podia não só alternar dátilos e espondeus e no último pé espondeus e troqueus, e por isso ter entre 13 e 17 sílabas, o hexâmetro vernáculo de Carlos Alberto Nunes pode apenas ter entre 16 e 18 
sílabas, conforme o último pé seja troqueu, dátilo ou mesmo oxítona, como se exemplificará a seguir.

Outro obstáculo é manter tônica a sílaba inicial do verso relativa à sílaba longa, de dátilo ou de espondeu, que sempre inicia o hexâmetro datílico, de sorte que Carlos Alberto Nunes teve que modificar o hexâmetro, que assumiu características próprias:

- a primeira sílaba tônica pode situar-se tanto na primeira como na segunda sílaba do verso, embora a preferência é que incida de fato na primeira sílaba. Desse modo, o primeiro pé pode assumir duas configurações: - “ (dátilo, "Canta-me", Ilíada, I, 1) ou “ - ("e como").

- possui 17 ou 18 sílabas. Possui 17, com os cinco primeiros pés datílicos, e o último troqueu (- ${ }^{\smile}$ ), que ocorre na maioria absoluta dos casos:

$\begin{array}{ccccccccccccccccc}1 & 2 & 3 & 4 & 5 & 6 & 7 & 8 & 9 & 10 & 11 & 12 & 13 & 14 & 15 & 16 & 17 \\ \text { Can } \mid \text { ta } \mid & \text {-me a } \mid \text { có } \mid \text { le } \mid \text { ra }- \text { ó } \mid \text { deu } \mid & \text { sa! } \mid & - \text { fu } \mid & \text { nes } \mid \text { ta } \mid \text { de A } \mid \text { qui } \mid \text { les } \mid \text { Pe } \mid \text { li } \mid \text { da }\end{array}$

(Ilíada, I, 1)

Possui 18 com todos os seis pés datílicos, inclusive o último:

$\begin{array}{llllllllllllllllll}1 & 2 & 3 & 4 & 5 & 6 & 7 & 8 & 9 & 10 & 11 & 12 & 13 & 14 & 15 & 16 & 17 & 18\end{array}$

e a $\mid$ san $\mid$ ta $|\mathrm{Ci}|$ la, e $\mid$ que $\mid$ tens $\mid$ o $\mid$ co $\mid$ man $\mid$ do $\mid$ su $\mid$ pre $\mid$ mo $\mid$ de $\mid$ Tê $\mid$ ne $\mid$ do

- a ocorrência de diérese é determinada pela necessidade de cumprir o hexâmetro, que a impõe mediante compasso sempre marcado pelas tônicas na primeira (ou segunda), quarta, sétima, décima, décima terceira e décima sexta sílabas.

- permite a possibilidade de interpretação ${ }^{6}$ de anacruses, igualmente marcada pelo ritmo, sem que no entanto esta seja uma característica recorrente.

O ritmo datílico predomina na leitura do poema, e era justamente esse o objetivo do tradutor. Como já dissemos, esse ritmo marca o gênero das antigas epopeias greco-romanas e é o principal recursos pelo qual o tradutor aproxima o leitor do texto de origem, da oralidade com que se divulgava e transmitia a narrativa, do que significavam as rapsódias no mundo antigo e de toda a tradição épica posterior, grega e romana.

\footnotetext{
${ }^{6}$ Como veremos, há casos em que a anacruse é uma das leituras possíveis da escanção, sendo paralela a uma leitura de deslocamento da sílaba tônica inicial para a segunda posição do pé.
} 


\title{
Schleiermacher, Nunes e Ovídio
}

Friedrich Schleiermacher (1768-1834), com o texto Über die verschiedenen Methoden des Übersezens, "Sobre os diferentes métodos de tradução" (Schleiermacher, 2001), em 1813 distingue dois modos de traduzir: aproximar o leitor do texto original ou aproximar o texto original do leitor. Sua escolha pelo primeiro método em detrimento do segundo tem caráter preceptivo para a teoria romântica da tradução: como se vê pelas versões contemporâneas que fizeram Goethe, Hölderlin, Voss, Schlegel e Humboldt (o próprio Schleiermacher traduziu Platão), o impulso tradutório dos alemães do período tinha como objetivo mais ou menos comum ampliar as fronteiras da língua alemã, apropriar-se do elemento estrangeiro para a elevar a própria cultura (cf. Berman, 2002). Nas palavras de Schleiermacher,

\begin{abstract}
Ou bem o tradutor deixa o escritor o mais tranquilo possível e faz com que o leitor vá a seu encontro, ou bem deixa o mais tranquilo possível o leitor e faz com que o escritor vá a seu encontro. Ambos os caminhos são tão completamente diferentes que um deles tem que ser seguido com o maior rigor [...]. No primeiro caso, o tradutor se esforça por substituir com seu trabalho o conhecimento da língua original, do qual carece o leitor. A mesma imagem, a mesma impressão que ele, com seu conhecimento da língua original, alcançou da obra, agora busca comunicá-la aos leitores, movendo-os, por conseguinte, até o lugar que ele ocupa e que propriamente lhe é estranho. (Schleiermacher, 2010: 57)
\end{abstract}

A mesma proposta é feita em termos um pouco diferentes, talvez mais claros no nosso contexto, por Pannwitz, no trecho acima citado.

Pensemos em Manoel Odorico Mendes (1799-1864), outro dos principais tradutores para o português de poesia épica grega e latina. A característica principal de suas traduções é a condensação, pois verte o total de hexâmetros datílicos em número menor de decassílabos portugueses, muito embora o hexâmetro antigo, que tem de 13 e 18 sílabas, seja mais longo do que o decassílabo, que tem de 10 a 12 sílabas. É conhecido seu esforço a fim de mostrar que nossa língua poderia ser tão ou mais sintética que as línguas declináveis, o que o leva a comprimir o português, naturalmente mais analítico que o grego antigo ou latim, em virtude da ausência de estrutura morfossintática de casos explícitos e consequente analiticidade de formas perifrásticas. $\mathrm{O}$ resultado a crítica tradutória muito frequentemente considerou "monstruoso" (apud Campos, 1992: 12) ou "muito notável" (Vasconcelos, 2009). O grau de helenização e latinização dos vocábulos, além da presença constante de construções que subvertem a sintaxe e a morfologia do português, resultam numa espécie de linguagem poética própria muito erudita e complexa. Tomemos um exemplo:

Lá coche, armas lá teve; e annúa o fado,

No orbe enthronal-a então já traça e tenta.

(Eneida, I vv.25-26)

Entretanto, a obra tradutória de Odorico Mendes, por utilizar decassílabos heróico e sáfico para gesta heróica, tal como fizera Camões, insere-se conservadoramente na tradição épica luso-brasileira, que ainda inclui 
Santa Rita Durão e Basílio da Gama. Além disso, justamente os motivos que parecem fazer da tradução odoricana representante aquele tipo que aproxima o leitor do texto original que Schleiermacher e Pannvitz defendem - estranheza sintática e latinização léxica deliberadas - são os que na verdade a afastam dessa posição, porque a erudição e a complexidade resultantes do esforço de síntese decerto não correspondem ao estilo oral da épica homérica nem ao estilo de Virgílio, que, apesar de ter composto de modo douto, segundo preceitos da poética helenística relativos à escrita, não faz uso tão constante de estruturas linguísticas e de vocabulário considerados arcaizantes, obscuros para sua época.

Por esse motivo, consideramos que as traduções de Carlos Alberto Nunes representam melhor o modo que aproxima o leitor do texto original, já que se recusa a usar o verso tradicional da épica luso-brasileira, preferindo plasmar uma espécie de hexâmetro português, estranho à métrica de nossa língua, para conseguir um ritmo semelhante ao da épica antiga, à semelhança do que Quinto Ênio fizera ao introduzir em latim o hexâmetro datílico na epopeia Anais, quando até se gabou de ter sido o primeiro a usar outro verso que não o tosco saturnino dos vates et faunei ${ }^{7}$ ). Ao fazer o que antes outros já haviam desejado $^{8}$, Nunes instaura na língua portuguesa uma tradição, que seguimos entre outros motivos porque o texto, dispondo de verso maior, recupera a simplicidade sintática de Homero e Virgílio, conserva a adequação vocabular sem recorrer a helenização ou latinização alambicada do português, e mantém praticamente mesmo número de versos ${ }^{9}$.

\section{Problemas e soluções}

O hexâmetro datílico latino é formado por, basicamente, 5 pés dátilos $\left(-^{-}\right)$mais um pé espondaico $(--)$ou um pé trocaico $\left(-{ }^{-}\right)$. Há, porém, uma certa flexibilidade no verso, pois um espondeu pode ser inserido no lugar de qualquer outro dos 5 dátilos, o que muito raramente ocorre no $5^{\circ}$ dátilo, desde que se mantenha ao menos um pé dátilo puro $\left(-^{-}\right.$) no verso (Crusius, 1951: $56)^{10}$, o que geralmente ocorre no $5^{\circ}$ pé. Podemos representar o hexâmetro datílico latino da seguinte forma:

$$
\begin{aligned}
& -\cdots /-\cdots /-\cdots /-\cdots /-\cdots /-\smile \\
& --/--/--1--1--1-- \text { (cf. possibilidades de substituição) }
\end{aligned}
$$

\footnotetext{
${ }^{7}$ Scripsere alii rem / vorsibus quos olim Faunei vatesque canebant. / [cum] neque Musarum scopulos... / nec dicti studiosus [quisquam erat] ante hunc. / Nos ausi reserare [...] "outros escreveram os factos em versos, que outrora cantavam Faunos e vates, quando nem os rochedos das Musas [...] nem havia antes de nós quem cuidasse da linguagem. Nós ousamos abrir-lhe as portas. Anais VII, 125-129, tradução de Maria (cf. introdução da tradução anapéstica dos hinos homéricos de Gramacho, 2003 Helena da Rocha Pereira - Pereira (2002).

8 Cf. "Introdução" de Gramacho para tradução anapéstica dos Hinos Homéricos, 2003.

9 Odorico Mendes reduziu a quantidade dos versos de maneira brutal, como na Odisseia, em que traduziu os 12106 hexâmetros por 9302 decassílabos; cf. Paulo Martins, "Caderno de Sábado", Jornal da Tarde de 30 de janeiro de 1999, acessível em http://letrasartes.blogspot.com/2007/06/odorico-mendes-beleza-e-engenho-para.html.

${ }^{10} \mathrm{O}$ autor apresenta, ainda, a única exceção da poesia latina.
} 
O esquema mostra que as seis possibilades de substituição, se combinadas umas com as outras, dão ao hexâmetro antigo inúmeras variações. Entretanto, ao "traduzir" o hexâmetro datílico latino para o português, Carlos Alberto teve que fixá-lo com cinco pés dátilos e sexto pé quase sempre trocaico, raramente dátilo, pois, como vimos, não se consegue utilizar espondeu em português, e a única possibilidade de variar que restou ao tradutor foi substiuir o troqueu final por um dátilo, ou em outras palavras, usar verso grave ou verso esdrúxulo. Assim, o hexâmetro criado por Carlos Alberto Nunes ser é mais rígido do que o antigo.

O esquema mostra também que a primeira sílaba do hexâmetro antigo, independentemente de começar com dátilo ou com espondeu, é sempre longa, tornando-se como que marca do verso, e nossa maior dificuldade, ao empregar o hexâmetro português, foi manter sempre tônica a sílaba inicial do verso. Carlos Alberto Nunes mantém preferencialmente tônica a primeira sílaba, mas encontram-se exemplos da mesma dificuldade na Ilíada traduzida por ele:

1) que o repeliu com dureza, assacando-lhe insultos pesados (I, 25)

2) Somente ao peito do Atrida Agamémnone o alvitre desprouve (I, 24)

No exemplo, 1 não há nenhuma silába tônica até a quarta sílaba. Para que o verso comece com tônica, o pronome que e o pronome $o$, átonos por natureza, sofrem ditongação e ganham tonicidade, de modo o verso soa como hexâmetro datílico:

que o repeliu com dureza, assacando-lhe insultos pesados:

No exemplo 2, para que o verso comece com sílaba tônica, desloca-se o acento em somente: a palavra, em vez de ser naturalmente paroxítona, é lida como proparoxítona, com acento tônico em so-, conforme o seguinte esquema:

Somente ao peito do Atrida Agamémnone o alvitre desprouve

Esses dois recursos utilizados por Carlos Aberto Nunes para superar a dificuldade da tônica inicial parecem-nos muito forçados em vista da prosódia natural das palavras no português brasileiro. Apesar de algumas vezes utilizálos, preferimos outro recurso, que nos parece mais deixar naturais as palavras: a anacruse.

"Anacruse" designa na teoria musical um fenômeno muito parecido com o que ocorre na poesia. Walter Piston (1987: 207), ao falar sobre o início das frases musicais, diz: "Phrases do not necessarily begin on the first beat of the measure. Rhythmically they may start either with an anacrusis (upbeat) or with $a$ thesis (downbeat)". Douglas Moore (1981: 289) assim define a anacruse: "Cuando una melodia no comienza con una nota fuerte, las notas que preceden a la primera acentuada reciben el nombre de anacrusis rítmico". Nos tratados de versificação, é a sílaba ou sílabas que antecedem a tônica inicial de um verso e não são consideradas na escansão ${ }^{11}$. Ou seja, se em 1 considerarmos a primeira sílaba de somente como anacruse, lemos o verso da seguinte forma:

\footnotetext{
${ }^{11}$ Cf. Nougaret, § 293A, pp. 105-105, e Moisés, p. 200.
} 
Somente ao peito do Atrida Agamémnone o alvitre desprouve

Para que essa leitura seja possível, não pode haver a natural elisão entre $\mathrm{o}-e$ átono final de somente e o $-a$ de $a o$, que são computados como duas sílabas para compensar a desconsideração do -so. Carlos Alberto Nunes pode ter tido em mente a anacruse com elisão, que seria, assim, o terceiro modo de resolver o problema da tônica inicial. Seja como for, o deslocamento da tônica ou anacruse com elisão são procedimentos mutuamente exclusivos naquele lugar do verso: ou se emprega um, ou outro.

Ao traduzir empregamos a anacruse como alternativa para prover sílaba tônica em início de verso, o que acabou por flexibilizar o hexâmetro datílico de Carlos Alberto Nunes. Por fim, seguem alguns exemplos da nossa tradução das Metamorfoses de Ovídio, em que sublinhamos as sílabas em anacruse:

Da vida tão cedo levada de Eurídice, o fio renovai. (X, 31)

largaram. Ó Sísifo, e tu em tua pedra sentaste. Com lágrimas. (X, 44)

Gigantes e raios triunfantes esparsos nos campos de Flegra. (X, 151)

rendida ao fascínio do sol e forjada com o prumo dos dedos. (X, 285)

\section{Considerações finais}

O que apresentamos a seguir é tradução colaborativa de excerto do livro X das Metamorfoses de Ovídio como resultado de experimento iniciado em disciplinas de graduação, como dissemos; não se pretende definitiva, senão amostra do complexo trabalho de traduzir poeticamente a partir de princípio específico, emular Carlos Alberto Nunes imitando-lhe hexâmetros datílicos vernáculos, e, então, colocando-nos como primeiros êmulos logo depois dele, em segunda posição, instaurar em português ou ao menos colaborar para tanto, uma tradição métrica que só a partir da primeira imitação passa a existir. Muitos problemas ainda restaram, e o resultado que conseguimos pode não ser o mais bem acabado, mas o trabalho coletivo, as inúmeras discussões, a divergência de opinião, o diferente estágio de qualificação dos tradutores envolvidos - já que vários alunos nunca haviam tentado tradução poética antes - nos levaram ao prazeroso resultado que ora apresentamos.

Rodrigo Tadeu Gonçalves goncalvesrt@gmail.com Universidade Federal do Paraná 


\section{METAMORPHOSEON}

LIBER X, 1-297

1 Inde per inmensum croceo velatus amictu

aethera digreditur Ciconumque

Hymenaeus ad oras

tendit et Orphea nequiquam voce vocatur.

adfuit ille quidem, sed nec sollemnia verba

5 nec laetos vultus nec felix attulit omen.

fax quoque, quam tenuit, lacrimoso stridula fumo

usque fuit nullosque invenit motibus ignes.

exitus auspicio gravior: nam nupta per herbas

dum nova naiadum turba comitata vagatur,

10 occidit in talum serpentis dente recepto.

quam satis ad superas postquam Rhodopeius auras

deflevit vates, ne non temptaret et umbras,

ad Styga Taenaria est ausus descendere porta

perque leves populos simulacraque functa sepulcro

15 Persephonen adiit inamoenaque regna tenentem

umbrarum dominum pulsisque ad carmina nervis

sic ait: 'o positi sub terra numina mundi,

in quem reccidimus, quicquid mortale creamur,

si licet et falsi positis ambagibus oris

$\mathbf{2 0}$ vera loqui sinitis, non huc, ut opaca viderem

Tartara, descendi, nec uti villosa colubris

terna Medusaei vincirem guttura monstri:

causa viae est coniunx, in quam calcata venenum

\section{METAMORFOSES}

LIVRO X, 1-297

1 Vai-se Himeneu com o manto dourado luzente coberto

o Éter imenso percorre e dali se retira, seguindo

em busca da costa da Trácia ${ }^{12}$, em vão por Orfeu foi chamado.

Lá ele esteve presente por certo, mas não trouxe aos noivos

5 votos felizes, palavras solenes, semblantes alegres.

Também a tocha que o deus agitava faiscava incessante

e lacrimosa fumaça emanava, sem chama brotar.

$\mathrm{O}$ resultado foi mais tenebroso que o augúrio: a noiva

com jovem grupo de ninfas andando na relva sofreu

10 bote serpênteo em seu calcanhar e então pereceu.

Pós ter chorado o bastante até os deuses do plano de cima, às baixas sombras não quis o poeta deixar de rogar.

Indo ao Estige, ousou por Tenário ${ }^{13}$ portão deslocar-se

e por um povo levíssimo, por insepultos espectros.

15 Foi-se à Perséfone possuidora dos reinos funestos

e ao soberano das sombras, com canto, sua lira pulsando,

Ó deuses - disse - que regem o mundo debaixo da terra

onde cairemos nós todos que fomos plasmados mortais,

se vós permitis que, deixando de lado rodeios de boca

20 falsa, que fale a verdade, então esclareço: desci,

não com o intuito de ver este reino tartáreo sombrio

nem de prender os serpênteos pescoços do monstro medúsico.

A causa da vinda é a esposa, que, tendo pisado uma víbora,

${ }^{12}$ Região grega, incorporada posteriormente ao Império Romano. Fazia fronteira com o Rio Nestos e as margens do Danúbio. Com o estabelecimento da província da Mésia Inferior pelos Romanos, os limites ao norte passaram a ser as montanhas do Haimos.

${ }^{13}$ Portão do Hades. 
vipera diffudit crescentesque abstulit annos.

25 posse pati volui nec me temptasse negabo:

vicit Amor. supera deus hic bene notus in ora est;

an sit et hic, dubito: sed et hic tamen auguror esse,

famaque si veteris non est mentita rapinae,

vos quoque iunxit Amor. per ego haec loca plena timoris,

30 per Chaos hoc ingens vastique silentia regni,

Eurydices, oro, properata retexite fata.

omnia debemur vobis, paulumque morati

serius aut citius sedem properamus ad unam.

tendimus huc omnes, haec est domus ultima, vosque

35 humani generis longissima regna tenetis.

haec quoque, cum iustos matura peregerit annos,

iuris erit vestri: pro munere poscimus usum;

quodsi fata negant veniam pro coniuge, certum est

nolle redire mihi: leto gaudete duorum.'

40 Talia dicentem nervosque ad verba moventem

exsangues flebant animae; nec Tantalus undam

captavit refugam, stupuitque Ixionis orbis,

nec carpsere iecur volucres, urnisque vacarunt teve seus anos formosos roubados, infuso o veneno.

25 Quis suportá-lo e não negarei que o tentei tivesse tentado:

Venceu-me Amor; este deus que nas orlas de cima é famoso,

cá já não sei. Mas suponho que aqui o conheçam também:

Caso o sequestro famoso de antanho ${ }^{14}$ não seja mentira,

Uniu-vos Amor. Através destes campos repletos de horror,

30 peço, no caos infindável, nos vastos domínios quietos:

Da vida tão cedo levada de Eurídice, o fio renovai.

Todas as coisas devemos a vós; e ainda que um pouco

nós demoremos, mais cedo ou mais tarde convosco encontramos

Última sede é a vossa morada, cá todos chegamos

35 e possuireis os longuíssimos reinos do gênero humano.

Ela também quando os anos devidos madura cumprir,

vossa será por direito: qual dádiva a peço de volta.

Mas se os destinos negarem à esposa a vênia que imploro,

Certo não hei de voltar: alegrai-vos com a morte dos dois.

40 Enquanto coisas tão belas falava e cantava, choravam

almas exangues, sem vida: e Tântalo ${ }^{15}$ mesmo não tenta

ondas fugazes sorver, até a roda de Ixíon ${ }^{16}$ parou,

nem os abutres comeram o fígado ${ }^{17}$, as Dânaes as urnas

${ }^{14}$ Refere-se ao seqüestro de Perséfone por Hades.

15 Tântalo era rei (da Frígia ou da Lídia), e teve três filhos. Certa vez, tentando enganar os deuses, roubou os manjares divinos e serviu-lhes a carne do seu próprio filho. A tentativa foi considerada grande ofensa aos deuses, que o lançaram em um vale onde havia muita água e alimento, mas Tântalo foi sentenciado a nunca poder saciar a fome e a sede. Assim, quando se aproximava dos frutos das árvores, o vento os levava; quando tentava beber água, ela fugia.

${ }^{16}$ Ixion, na mitologia grega, era o rei da tribo mais antiga da Tessália, Lapitis, e filho de Ares. Casando-se com Dia, filha de Dioneu, prometeu ao sogro um dote valioso. Como não cumprisse a promessa, Dioneu roubou alguns cavalos de Ixion. Para resolver a contenda, Ixion propôs um duelo. Quando Dioneu chegou, Ixion o empurrou para uma fogueira, assassinando-o. Todos os reis vizinhos, inconformados com o ato brutal, se recusaram a fazer qualquer ritual que pudesse purificar Ixion. Entretanto, comovido com o seu desespero, Zeus o chama para que, no Olimpo, o pudessem julgar. Porém, em vez de ser grato, Ixion apaixona-se por Hera. Percebendo as intenções dele, Zeus faz uma nuvem com o aspecto de Hera e força Ixion a manter relação sexual com a nuvem, chamada de Nefele. Dessa união nasce o Centauro e todos os descendentes dessa raça ficaram conhecidos como Ixionidas. Expulso do Olimpo, Ixion foi atado a uma roda de fogo que giraria eternamente. 
Belides, inque tuo sedisti, Sisyphe, saxo.

45 tunc primum lacrimis victarum carmine fama est

Eumenidum maduisse genas, nec regia coniunx

sustinet oranti nec, qui regit ima, negare,

Eurydicenque vocant: umbras erat illa recentes

inter et incessit passu de vulnere tardo.

50 hanc simul et legem Rhodopeius accipit heros,

ne flectat retro sua lumina, donec Avernas

exierit valles; aut inrita dona futura.

carpitur adclivis per muta silentia trames,

arduus, obscurus, caligine densus opaca,

55 nec procul afuerunt telluris margine summae:

hic, ne deficeret, metuens avidusque videndi

flexit amans oculos, et protinus illa relapsa est, $\operatorname{largaram}^{18}$. Ó Sísifo, e tu em tua pedra sentaste $^{19}$. Com lágrimas,

45 diz-se, por causa do canto molharam-se os rostos das Fúrias ${ }^{20}$.

Não suportou o pedido negar nem a esposa real,

nem o que rege. Chamaram Eurídice. Ela entre sombras

recentes estava. Andava com passos mais lentos e ainda,

convalescia por causa de seu ferimento na perna.

50 Ao mesmo tempo o herói rodopeu ${ }^{21}$ a recebe e à lei,

de não voltar para trás o olhar ao subir as encostas

do vale averno, ou então os presentes seriam perdidos.

Íngreme trilha tomaram por mudos silêncios então,

Árdua, sombria, de luz desprovida por densa neblina.

55 E não estavam distantes das margens do sumo da terra -

Aqui, temendo a amada perder e ansioso por vê-la,

volve o amante seus olhos e ela num átimo esvai-se.

${ }^{17}$ Refere-se ao fígado de Prometeu, cujo castigo era o de que os abutres lhe comessem o fígado, que em seguida se regeneraria para ser novamente ser comido. O crime de Prometeu havia sido roubar o fogo dos deuses para dá-lo aos humanos, o que foi interpretado como uma ofensa à onipotência dos deuses.

${ }^{18}$ Dânaes,ou Danaides, são as netas de Belo (também chamadas de Belides). Belo tinha 50 filhas, e 49 delas mataram os maridos na noite de núpcias (a única que poupou o marido foi Hipermnestra). Por isso, foram obrigadas por Zeus a encher nos Infernos grandes tonéis sem fundo.

${ }^{19}$ Sísifo é um dos personagens mais astutos da mitologia. Certa vez, tendo presenciado o rapto de uma bela jovem por Zeus, chantageou o pai da moça para contar-lhe o paradeiro e quem era o raptor. Sabendo disso, Zeus mandou Tânatos, a morte, levá-lo para o mundo subterrâneo. Tecendo elogios à beleza de Tânatos e dizendo que pretendia colocar-lhe um colar, Sísifo acabou por acorrentá-la e mantâ-la prisioneira. Isso irritou tanto Hades como Ares, que precisavam dos préstimos de Tânatos para continuar a exercer seus poderes. Assim, Hades libertou Tânatos e levou Sísifo consigo. Já no inferno, Sísifo pediu a Hades que lhe desse um dia a mais na terra para poder vingar-se da esposa, que não lhe tinha dado funeral digno. Entretanto, a esposa não o havia enterrado porque Sísifo the havia pedido, e ele, assim, retomou o corpo mortal e enganou a morte mais uma vez. Dessa forma, Sísifo morreu de velhice mas, quando conduzido a Hades, foi condenado por causa da rebeldia, a rolar até o cume de uma montanha uma grande pedra de mármore que, tão logo ali chegava, rolava de volta ao ponto de partida.

${ }^{20}$ As Erínias, Eumênides ou Fúrias eram personificações da vingança, semelhantes a Nêmesis, porém encarregadas de punir os mortais. Seus nomes eram Tisífone (Castigo), Megera (Rancor) e Alecto (Implacável). Viviam nas profundezas do Hades e tinham a função de torturar almas que Hades e Perséfone haviam julgado culpadas. Segundo a Teogonia, nasceram das gotas do sangue que caíram sobre Gaia quando o deus Urano foi castrado por Cronos. Por ser extremamente cruéis, eram chamadas "Benevolentes" ou "Veneradas" por eufemismo para que se lhes atraísse a cólera. De tão implacáveis, não aceitavam sacrifícios nem se comoviam com o bom comportamento de alguém. Por isso, é grande o impacto que Orfeu lhes causou a ponto de fazê-las chorar.

${ }^{21}$ De Ródope, cordilheira situada entre a Grécia e a Bulgária. 
bracchiaque intendens prendique et prendere certans

nil nisi cedentes infelix arripit auras.

60 iamque iterum moriens non est de coniuge quicquam

questa suo (quid enim nisi se quereretur amatam?)

supremumque 'vale,' quod iam vix auribus ille

acciperet, dixit revolutaque rursus eodem est.

Non aliter stupuit gemina nece coniugis Orpheus,

$\mathbf{6 5}$ quam tria qui timidus, medio portante catenas,

colla canis vidit, quem non pavor ante reliquit,

quam natura prior saxo per corpus oborto,

quique in se crimen traxit voluitque videri

Olenos esse nocens, tuque, o confisa figurae,

70 infelix Lethaea, tuae, iunctissima quondam

pectora, nunc lapides, quos umida sustinet Ide.

orantem frustraque iterum transire volentem

portitor arcuerat: septem tamen ille diebus

squalidus in ripa Cereris sine munere sedit;

75 cura dolorque animi lacrimaeque alimenta fuere.

esse deos Erebi crudeles questus, in altam

se recipit Rhodopen pulsumque aquilonibus Haemum.

Tertius aequoreis inclusum Piscibus annum

finierat Titan, omnemque refugerat Orpheus

$\mathbf{8 0}$ femineam Venerem, seu quod male cesserat illi,

sive fidem dederat; multas tamen ardor habebat
Ele seus braços estira, pensando em retê-la consigo,

O infeliz nada toma a não ser o ar que foge. E assim,

60 Ela, morrendo outra vez, não culpou o marido por nada:

O que havia ele feito, senão desejar sua amada?

O último adeus de difícil escuta o ouvido repara

e ela regressa outra vez aos infernos. E nisso, Orfeu,

pasmo com gêmina morte da cônjuge estático fica

65 não diferente daquele que triplo pescoço canino

(freios portava a cabeça do meio) de Cérbero viu,

teve seu corpo adornado de pedras, e a alma o deixou.

Tal como Olenos que o crime da esposa assumiu e que então

quis ele mesmo tomar toda culpa; e tu, ó soberba,

70 Létea infeliz, e os outrora juntíssimos corpos dos dois

hoje tornados em pedra, no alto do úmido $\mathrm{Ida}^{22}$.

Vãos os desejos e rogos, Caronte proíbe voltarem.

Mísero, Orfeu sete dias sentou-se na margem do rio

Nada comia, tributo nenhum que viesse de Ceres

75 E ele nutriam-no a dor de sua alma, as lúgubres lágrimas.

Ínferos deuses, por que a crueldade? O amante reclama.

busca alta Ródope, e Haemo, batido dos ventos do norte ${ }^{23}$.

Eis que o terceiro Titã todo o ciclo de Peixes completa ${ }^{24}$,

Antes amante, ele agora evitava o amor feminino.

$80 \mathrm{Ou}$ porque a história com Eurídice mal terminara ou então

porque o infeliz desta forma jurou. No entanto o ardor

\footnotetext{
${ }^{22}$ Oleno e Létea eram um casal que vivia no monte Ida. Certa vez, Létea teria dito que era mais bonita do que qualquer uma das deusas. As deusas, ofendidas, transformaram Létea em pedra. Oleno, desesperado, pediu para que seu destino fosse igual ao da esposa e que pudessem ficar juntos e foi, então, também tranformado em pedra.

${ }^{23} \mathrm{Na}$ mitologia grega, Aemo era um rei que comparou a si e a sua esposa, Ródope, a Zeus e Hera. Pela blasfêmia, foram transformados em montes: Monte Aemo e Montanha Ródope. Essa cadeia de montes fica na Trácia e é, modernamente, chamada de Grande Bálcã.

${ }^{24}$ Completar todo o ciclo de Peixes significa que o sol completou um ano.
} 
iungere se vati, multae doluere repulsae.

ille etiam Thracum populis fuit auctor amorem

in teneros transferre mares citraque iuventam

$\mathbf{8 5}$ aetatis breve ver et primos carpere flores.

Collis erat collemque super planissima campi

area, quam viridem faciebant graminis herbae:

umbra loco deerat; qua postquam parte resedit

dis genitus vates et fila sonantia movit,

90 umbra loco venit: non Chaonis afuit arbor,

non nemus Heliadum, non frondibus aesculus altis,

nec tiliae molles, nec fagus et innuba laurus,

et coryli fragiles et fraxinus utilis hastis

enodisque abies curvataque glandibus ilex

95 et platanus genialis acerque coloribus inpar

amnicolaeque simul salices et aquatica lotos

perpetuoque virens buxum tenuesque myricae

et bicolor myrtus et bacis caerula tinus.

vos quoque, flexipedes hederae, venistis et una

100 pampineae vites et amictae vitibus ulmi

ornique et piceae pomoque onerata rubenti

arbutus et lentae, victoris praemia, palmae

et succincta comas hirsutaque vertice pinus,

grata deum matri, siquidem Cybeleius Attis

105 exuit hac hominem truncoque induruit illo.

Adfuit huic turbae metas imitata cupressus,

nunc arbor, puer ante deo dilectus ab illo,

qui citharam nervis et nervis temperat arcum.

namque sacer nymphis Carthaea tenentibus arva

110 ingens cervus erat, lateque patentibus altas muitas a unir-se com o vate exortava e por isso sofriam.

Ele também foi o autor, para os povos da Trácia, dos cantos

que para os jovens sensíveis infundem amor e ensinam

85 à juventude das flores primeiras da breve estação desfrutar.

Uma colina existia e planíssima área de campos

sobre a colina, que as ervas gramíneas mais verde tornavam.

Sombra faltava ao lugar; mas depois que assentou-se no campo

o vate de deuses gerado e as cordas sonantes tocou,

90 Sombra chegou ao lugar: nem o arbusto de Cáon faltou,

Nem o helíade bosque, nem o ésculo de alta folhagem,

a tília suave, a faia e o loureiro que é sempre virgem,

a fraca aveleira, o freixo tão útil para hastes de guerra,

o abeto sem nós e a azinheira curvada por seus muitos frutos,

95 o plátano fértil e alegre e o bôrdo de cores tão ímpares,

o lótus aquático e junto o salgueiro de beira de rio,

o buxinho de verde perpétuo e o sutil tamarindo,

a murta bicólor e até a figueira cerúlea de figos.

Vós, trepadeiras as hedras, viestes também e convosco

100 tantas parreiras de vinhas e o olmo forrado de parras

o negro abeto de pomo vermelho e o freixo silvestre

e a medronheira e palmeiras tranqüilas, troféus de vitórias,

e o alto pinheiro de folhas dispersas e hirsuto no vértice,

(que) é o favorito da mãe dos divinos, já que Átis de Cíbele

105 na ocasião, despojou-se e enrijou em madeira o jovem.

Junto das plantas estava Cipreste com forma de cone:

árvore agora, outrora um menino dileto do deus

que cordas da cítara e cordas do arco tocava tão bem.

Junto das ninfas dos campos cartéios vivia um sagrado

110 Cervo vistoso, que sombra vastíssima a fronte provia. 
ipse suo capiti praebebat cornibus umbras.

cornua fulgebant auro, demissaque in armos

pendebant tereti gemmata monilia collo.

bulla super frontem parvis argentea loris

115 vincta movebatur; parilesque ex aere nitebant

auribus e geminis circum cava tempora bacae;

isque metu vacuus naturalique pavore

deposito celebrare domos mulcendaque colla

quamlibet ignotis manibus praebere solebat.

120 sed tamen ante alios, Ceae pulcherrime gentis,

gratus erat, Cyparisse, tibi: tu pabula cervum

ad nova, tu liquidi ducebas fontis ad undam,

tu modo texebas varios per cornua flores,

nunc eques in tergo residens huc laetus et illuc

125 mollia purpureis frenabas ora capistris.

Aestus erat mediusque dies, solisque vapore

concava litorei fervebant bracchia Cancri:

fessus in herbosa posuit sua corpora terra

cervus et arborea frigus ducebat $a b$ umbra.

$\mathbf{1 3 0}$ hunc puer inprudens iaculo Cyparissus acuto

fixit et, ut saevo morientem vulnere vidit,

velle mori statuit. quae non solacia Phoebus

dixit et, ut leviter pro materiaque doleret,

admonuit! gemit ille tamen munusque supremum

135 hoc petit a superis, ut tempore lugeat omni.

iamque per inmensos egesto sanguine fletus

in viridem verti coeperunt membra colorem,

et, modo qui nivea pendebant fronte capilli,

horrida caesaries fieri sumptoque rigore
Resplandeciam os chifres ingentes ornados com ouro;

Jóias, colares de gemas do torso do cervo pendiam.

Um amuleto de prata tão velho quanto ele dançava

Preso na testa com tiras pequenas de couro. Em sua

115 Fronte ao redor do orifício da orelha brilhava um par

Gêmeo de pérolas. Medo nenhum nem pavor natural

Tinha dos homens. Gostava de as casas honrar, e dava,

Muito amigável, o pescoço aos afagos das mãos dos estranhos.

Mais do que o povo da Ceia belíssima, tu, ó Cipreste,

120 Tinhas o amor do animal. Quem lhe dava a comida, achava

Fontes e ondas tão límpidas e o conduzia, eras tu.

Tu eras quem várias flores atava à cabeça do cervo.

Qual cavaleiro montado feliz iam a todo lado.

Rédeas purpúreas usavas a fim de frear o animal

125 Boca macia ficava detida de forma suave.

Meio do dia, fazia calor. E, por causa do sol,

os côncavos braços de Câncer ferviam as águas litóreas:

Pôs o seu corpo cansado no chão verdejante o animal,

Para com a sombra das árvores ter o refresco do sol.

130 O imprudente Cipreste transpassa uma lança afiada

nele, e ao vê-lo morrer com ferida fatal decidiu-se

querer morrer. E Apolo palavras amenas não disse, mas

aconselhou que sofresse por tal situação de maneira mais leve,

Geme o menino contudo e suplica aos ofícios divinos

$135 \mathrm{E}$ isso pediu aos supremos: por todo o sempre chorasse.

Pela vontade dos deuses chorou té que sangue verteu.

Verdes ficaram, então, os seus membros, e da alva fronte

A cabeleira que outrora pendia se torna afinal

hórrida juba e, tomado de duro rigor, vira árvore, 
140 sidereum gracili spectare cacumine caelum.

ingemuit tristisque deus 'lugebere nobis

lugebisque alios aderisque dolentibus' inquit.

Tale nemus vates attraxerat inque ferarum

concilio, medius turbae, volucrumque sedebat.

145 ut satis inpulsas temptavit pollice chordas

et sensit varios, quamvis diversa sonarent,

concordare modos, hoc vocem carmine movit:

'ab Iove, Musa parens, (cedunt Iovis omnia regno)

carmina nostra move! Iovis est mihi saepe potestas

150 dicta prius: cecini plectro graviore Gigantas

sparsaque Phlegraeis victricia fulmina campis.

nunc opus est leviore lyra, puerosque canamus

dilectos superis inconcessisque puellas

ignibus attonitas meruisse libidine poenam.

155 'Rex superum Phrygii quondam Ganymedis amore

arsit, et inventum est aliquid, quod Iuppiter esse,

quam quod erat, mallet. nulla tamen alite verti

dignatur, nisi quae posset sua fulmina ferre.

nec mora, percusso mendacibus aere pennis

160 abripit Iliaden; qui nunc quoque pocula miscet

invitaque Iovi nectar Iunone ministrat.

'Te quoque, Amyclide, posuisset in aethere Phoebus,

tristia si spatium ponendi fata dedissent.

qua licet, aeternus tamen es, quotiensque repellit

165 ver hiemem, Piscique Aries succedit aquoso,

tu totiens oreris viridique in caespite flores.

te meus ante omnes genitor dilexit, et orbe
140 copa graciosa começa a olhar para os céus estrelados.

Triste, o deus suspirante: "Serás lamentado por nós

lamentarás outros tristes e atenderás aos que sofrem".

Tal era a selva que o vate até ali seduzira e na qual

entre o concílio de feras e a turba de aves sentava-se.

145 Como tentasse bastante com os dedos as cordas dispersas,

vários compassos em acordo sentiu, apesar de soarem

notas diversas, a voz comoveu com este canto destarte:

"Musa materna, de Júpiter -- tudo ao seu trono se curva, --

nossos poemas inspira! Outrora por mim seu poder

150 foi muitas vezes cantado: com lira mais grave cantei

Gigantes e raios triunfantes esparsos nos campos de Flegra ${ }^{25}$.

Lira mais leve agora se faz necessária: cantemos

jovens que eram diletos dos deuses e moças, que afoitas

pelas proibidas paixões, por luxúria castigo sofreram.

$155 \mathrm{O}$ rei dos deuses se ardeu, certa vez, pelo amor de um troiano,

de Ganimedes, e foi descoberto que o deus preferia

ser dessa nova maneira. Porém, não julgava ser digno

em ave qualquer transformar-se senão na que seus raios porta.

Logo, por asas fingidas o céu todo foi percorrido, e

160 Jove o Ilíade rapta; ele hoje prepara as bebidas

assim como serve do néctar a Jove e a Juno agastada.

Febo teria te posto no éter também, Amiclida,

Se tempo bastante tivessem cedido os fados sombrios.

Contudo és eterno, do modo que é lícito: sempre que o inverno

165 Pela floral estação é afastado, e a peixes aquoso

Áries sucede, tu nasces também e floresces na relva.

Antes de todos o meu genitor preferiute, e Delfos,

\footnotetext{
${ }^{25}$ Um campo de batalhas, aparentemente na Macedônia.
} 
in medio positi caruerunt praeside Delphi,

dum deus Eurotan inmunitamque frequentat

170 Sparten, nec citharae nec sunt in honore sagittae:

inmemor ipse sui non retia ferre recusat,

non tenuisse canes, non per iuga montis iniqui

ire comes, longaque alit adsuetudine flammas.

iamque fere medius Titan venientis et actae

$\mathbf{1 7 5}$ noctis erat spatioque pari distabat utrimque,

corpora veste levant et suco pinguis olivi

splendescunt latique ineunt certamina disci.

quem prius aerias libratum Phoebus in auras

misit et oppositas disiecit pondere nubes;

180 reccidit in solidam longo post tempore terram

pondus et exhibuit iunctam cum viribus artem.

protinus inprudens actusque cupidine lusus

tollere Taenarides orbem properabat, at illum

dura repercusso subiecit verbere tellus

185 in vultus, Hyacinthe, tuos. expalluit aeque

quam puer ipse deus conlapsosque excipit artus,

et modo te refovet, modo tristia vulnera siccat,

nunc animam admotis fugientem sustinet herbis.

nil prosunt artes: erat inmedicabile vulnus.

190 ut, siquis violas rigidumve papaver in horto

liliaque infringat fulvis horrentia linguis,

marcida demittant subito caput illa vietum

nec se sustineant spectentque cacumine terram:

sic vultus moriens iacet et defecta vigore

195 ipsa sibi est oneri cervix umeroque recumbit.

"laberis, Oebalide, prima fraudate iuventa,"
No centro do Orbe, esteve privada de seu guardião,

Enquanto Apolo freqüenta Eurotas e Esparta sem muros,

170 Honras ao arco não presta ou à cítara. Febo, esquecido

Das coisas que próprias lhe são, cães, redes portar não se nega,

Nem, companheiro, a vagar pelo cimo de montes oblíquos,

E cresce no peito uma chama nutrida por longo convívio.

Meio caminho havia o Titã percorrido, e igual

175 Era o espaço existente entre a noite passada e a vindoura

Livram-se os corpos das vestes, luzentes tornando-se ungidos

de óleo tirado à oliveira, e certame de disco iniciam.

Tendo-o Apolo vibrado, às brisas aéreas o envia

Nuvens dispersas ficando, por causa de seu grande peso.

180 Longo é o tempo que passa até em sólida terra cair

Arte admirável mostrando casada a uma força tremenda.

Ávido e sem perder tempo se apressa imprudente o Tenárida

A fim de o disco alcançar, pois deseja lançá-lo também.

A dura terra, no entanto, com golpe certeiro atirou-o,

185 Teu pobre rosto acertando, Jacinto. Empalideceu,

Tal qual o próprio menino, o deus que debalde lhe acolhe

Os membros fracos caídos, e ora procura que o ânimo

Possa ao teu corpo voltar, ora as tristes feridas enxuga,

Busca reter-te o espírito agora, co' a ajuda de ervas,

190 Mas são inúteis suas artes: a chaga se mostra incurável.

Como se alguém violetas quebrasse em meio ao jardim

Ou rebentasse a papoula ou os lírios de língua amarela, que

Lânguidos cedem de súbito, a terra mirando, incapazes

De sustentar-se, enjambrados: assim jaz a face morrendo

195 Abandonada de viço, vergando e afundando nos ombros.

"Escapas-me, Ebálida, a flor da tua idade mais tenra roubada", 
Phoebus ait "videoque tuum, mea crimina, vulnus.

tu dolor es facinusque meum: mea dextera leto

inscribenda tuo est. ego sum tibi funeris auctor.

200 quae mea culpa tamen, nisi si lusisse vocari

culpa potest, nisi culpa potest et amasse vocari?

atque utinam tecumque mori vitamque liceret

reddere! quod quoniam fatali lege tenemur,

semper eris mecum memorique haerebis in ore.

205 te lyra pulsa manu, te carmina nostra sonabunt,

flosque novus scripto gemitus imitabere nostros.

tempus et illud erit, quo se fortissimus heros

addat in hunc florem folioque legatur eodem."

talia dum vero memorantur Apollinis ore,

210 ecce cruor, qui fusus humo signaverat herbas,

desinit esse cruor, Tyrioque nitentior ostro

flos oritur formamque capit, quam lilia, si non

purpureus color his, argenteus esset in illis.

non satis hoc Phoebo est (is enim fuit auctor honoris):

215 ipse suos gemitus foliis inscribit, et AI AI

flos habet inscriptum, funestaque littera ducta est.

nec genuisse pudet Sparten

Hyacinthon: honorque

durat in hoc aevi, celebrandaque more priorum

annua praelata redeunt Hyacinthia pompa.

220 'At si forte roges fecundam Amathunta metallis,

an genuisse velit Propoetidas, abnuat aeque

atque illos, gemino quondam quibus aspera cornu

frons erat, unde etiam nomen traxere Cerastae.

ante fores horum stabat Iovis Hospitis ara;

225 ignarus sceleris quam siquis sanguine tinctam
Exclama Febo. "E teu ferimento, meu crime, contemplo.

És minha dor e meu crime. A culpa minha destra carrega

De tua ruína. Sou eu o autor do teu fúnebre fado.

200 Qual minha culpa, contudo, a não ser que se possa chamar

Culpa querer divertir-se, a não ser que se possa chamar

Culpa, também, ter amado. Se ao menos morrendo contigo

Fosse possível trazer-te de volta a esta vida. Mas, já que nos prende

A lei fatal, tua memória jamais deixará minha boca.

205 Nossos poemas, a lira vibrada por esta mão, eles

Hão de fazer-te ecoar, e uma nova flor nossos lamentos

Escritos trará. E haverá uma época em que um herói

Ímpar em força terá o seu nome, então, lido em suas folhas."

Enquanto tais coisas a boca de Apolo em verdade dizia,

210 Eis que o sangue vertido no solo e que a grama marcara

Não mais é sangue e, de cor mais brilhante que a púrpura tíria

Nasce uma flor e uma forma qual lírio assume, embora

Púrpura fosse, enquanto que argêntea é a cor desse outro.

Isso não foi o bastante p'ra Febo (pois ele era o autor

215 Dessa homenagem). O próprio lamento inscreveu nesta folha

E "AIAI" as letras funestas a flor em suas folhas carrega.

Esparta não se envergonha de ter produzido Jacinto:

Todos os anos celebra-se, como os antigos, a honra,

À frente de todos retorna em desfile a pompa jacíntia.

220 Se perguntasses a Amatos, fecunda em metais, se teria

as Propetides gerado, esta terra diria que não,

como também os de fronte espinhosa enfeitada com chifres,

donde por isso descobre-se a origem do nome Cerasta.

Nas suas portas, havia um altar de Jove, Hospitaleiro

225 Se um estrangeiro, ignorante do crime, tivesse o altar 
advena vidisset, mactatos crederet illic

lactantes vitulos Amathusiacasque bidentes:

hospes erat caesus! sacris offensa nefandis

ipsa suas urbes Ophiusiaque arva parabat

230 deserere alma Venus. "sed quid loca grata, quid urbes

peccavere meae? quod" dixit "crimen in illis?

exilio poenam potius gens inpia pendat

vel nece vel siquid medium est mortisque fugaeque.

idque quid esse potest, nisi versae poena figurae?"

235 dum dubitat, quo mutet eos, ad cornua vultum

flexit et admonita est haec illis posse relinqui

grandiaque in torvos transformat membra iuvencos.

'Sunt tamen obscenae Venerem Propoetides ausae

esse negare deam; pro quo sua numinis ira

240 corpora cum fama primae vulgasse feruntur,

utque pudor cessit, sanguisque induruit oris,

in rigidum parvo silicem discrimine versae.

'Quas quia Pygmalion aevum per crimen agentis

viderat, offensus vitiis, quae plurima menti

245 femineae natura dedit, sine coniuge caelebs

vivebat thalamique diu consorte carebat.

interea niveum mira feliciter arte

sculpsit ebur formamque dedit, qua femina nasci

nulla potest, operisque sui concepit amorem.

250 virginis est verae facies, quam vivere credas,

et, si non obstet reverentia, velle moveri:

ars adeo latet arte sua. miratur et haurit

pectore Pygmalion simulati corporis ignes.

saepe manus operi temptantes admovet, an sit visto, tingido de sangue, acharia: novilhos e ovelhas

novas de Amatos no altar sacrifício teriam sofrido.

Sacrificaram estrangeiros! E Vênus bondosa ofendida

por crimes tão graves, decide ela mesma deixar

230 suas cidades e os campos Ofiúsos: "Diletos locais,

em que pecaram" diz Vênus "Que crime fizeram com eles?

Ímpia, a tribo que pague uma pena melhor que o exílio

ou homicídio, ou algo entre a morte e a fuga. E que pode

ser esta pena, senão a figura mudada, vertida"

235 Vênus, enquanto decide em que irá transformá-los, aos chifres

os olhos volve e lembra que pode mantê-los com eles;

verte os Cerastas de membros enormes em touros ferozes.

E as Propetides vulgares ousaram negar que alma Vênus

fosse uma deusa. Por isso, pela ira divina, elas foram

240 Iniciadoras da prostituição, como conta a história;

Cessa o pudor e tão rígido o sangue tornou-se nas faces

Que em pouco espaço de tempo elas foram vertidas em pedras.

Pigmalião, tendo-as visto entregues ao crime perpétuo

Em meio aos vícios odiosos que dons foram da natureza

245 para o espírito mau da mulher, sem esposa, solteiro

há muito tempo vivia carente de esposa no tálamo.

Enquanto isso feliz e com arte admirável esculpiu

O níveo marfim, concedendo-lhe forma: a de uma mulher

Como nenhuma jamais. Por sua obra encantado ficou.

250 Bela, a forma é de virgem real, que acreditas viver

E pensarias querer se mover, se não fosse restrita:

tal é a arte que esconde sua arte. Admira-se e sofre

No coração, com os fogos que emanam do corpo forjado.

Vezes sem conta, as mãos se aproximam, tateantes, da obra, 
255 corpus an illud ebur, nec adhuc ebur esse fatetur.

oscula dat reddique putat loquiturque tenetque

et credit tactis digitos insidere membris

et metuit, pressos veniat ne livor in artus,

et modo blanditias adhibet, modo grata puellis

260 munera fert illi conchas teretesque lapillos

et parvas volucres et flores mille colorum

liliaque pictasque pilas et ab arbore lapsas

Heliadum lacrimas; ornat quoque vestibus artus,

dat digitis gemmas, dat longa monilia collo,

265 aure leves bacae, redimicula pectore pendent:

cuncta decent; nec nuda minus formosa videtur.

conlocat hanc stratis concha Sidonide tinctis

adpellatque tori sociam adclinataque colla

mollibus in plumis, tamquam sensura, reponit.

270 'Festa dies Veneris tota celeberrima Cypro

venerat, et pandis inductae cornibus aurum

conciderant ictae nivea cervice iuvencae,

turaque fumabant, cum munere functus ad aras

constitit et timide "si, di, dare cuncta potestis,

275 sit coniunx, opto," non ausus "eburnea virgo"

dicere, Pygmalion "similis mea" dixit "eburnae."

sensit, ut ipsa suis aderat Venus aurea festis,

vota quid illa velint et, amici numinis omen,

flamma ter accensa est apicemque per aera duxit.

280 ut rediit, simulacra suae petit ille puellae

incumbensque toro dedit oscula: visa tepere est;

admovet os iterum, manibus quoque pectora temptat:

temptatum mollescit ebur positoque rigore
255 Que, até aqui não consegue saber se é corpo ou marfim.

Dá beijos, pensa de volta ganhá-los, conversa, segura-a,

Crê que, ao tocá-la, afunda os seus dedos em membros macios,

Teme que, tendo-os forçado demais, lividez não perceba,

Ora ele emprega carícias e ora, o que apraz às garotas,

260 Leva presentes para ela: são pérolas mui bem formadas,

Pedrinhas, minúsculos pássaros, flores de cores variadas,

Lírios tingidos, e as lágrimas de âmbar de Helíades árvores

Com vestimentas belíssimas veste-lhe os membros também

Pedras preciosas aos dedos e longos colares ao colo,

265 Aljofres polidos à orelha e laços pendendo do peito.

Tudo cai bem, não sendo ela menos esplêndida nua.

Ele a coloca num leito tingido de púrpura tíria,

Sócia do leito lhe chama e descansa o pescoço inclinado

em travesseiros de plumas suaves, tal como sentisse.

270 Tinha chegado a data da festa de Vênus, a mais

Célebre em todo o Chipre e - banhados os cornos a ouro -

Foram sangradas, a golpes na nuca, as níveas novilhas.

Incensos queimavam ao tempo que, fazendo uma oferta,

tímido, encosta diante do altar e suplica: "se, deuses,

275 tudo podeis conceber, desejo uma esposa" e hesitou

e ao invés de dizer "de marfim" disse "igual a que fiz".

Já que lá estava áurea Vênus em seu festival percebeu

qual o sentido das súplicas; e eis o presságio da deusa:

chamas três vezes arderam com as pontas nas nuvens luzindo.

280 Tendo voltado procura ele a estátua de sua donzela;

por sobre o leito se inclina beijando-a: parece-lhe cálida;

beija outra vez os seus lábios e toca com as mãos os seus seios:

sendo tocado o marfim amolece e, deposta a rijeza, 
subsidit digitis ceditque, ut Hymettia sole

285 cera remollescit tractataque pollice multas

flectitur in facies ipsoque fit utilis usu.

dum stupet et dubie gaudet fallique veretur,

rursus amans rursusque manu sua vota retractat.

corpus erat! saliunt temptatae pollice venae.

290 tum vero Paphius plenissima concipit heros

verba, quibus Veneri grates agat, oraque tandem

ore suo non falsa premit, dataque oscula virgo

sensit et erubuit timidumque ad lumina lumen

attollens pariter cum caelo vidit amantem.

295 coniugio, quod fecit, adest dea, iamque coactis

cornibus in plenum noviens lunaribus orbem

illa Paphon genuit, de qua tenet insula nomen. cede e se molda ao contorno dos dedos, qual cera da Himétia

285 rendida ao fascínio do sol e forjada com o prumo dos dedos

em muitas formas se altera e o seu uso é o que a torna tão útil.

enquanto fica abismado, alegra-se e teme enganar-se,

apaixonado, com a mão, ele toca e retoca o presente.

Viva ela estava: pulsavam as veias ao toque dos dedos.

290 Filho de Pafos, o herói concebia palavras legítimas

com as quais graças a Vênus bondosa regeu, finalmente ele

pôde beijar uma boca não falsa de forma que a virgem

sente seu beijo e enrubesce e levanta seus tímidos olhos

para a clareza entrevendo conjuntos o céu e o amante.

295 Vênus assiste então ao casamento que havia desperto.

Quando completam os cornos da lua o nono período ${ }^{26}$,

Páfos nasceu, e foi dele que a ilha seu nome ganhou.

Equipe de tradução:

Álvaro Kasuaki Fujihara, Elias dos Santos Paraizo Jr., Gabriel Dória Rachwal, Leandro Dorval Cardoso, Livy Maria Real Coelho, Luana de Conto, Marianna Sella, Marina Chiara Legroski, Rodrigo Tadeu Gonçalves;

Lorena Pantaleão, Luciana Kimi Iwamoto goncalvesrt@gmail.com Universidade Federal do Paraná

\footnotetext{
${ }^{26}$ Os nove meses da gestação.
} 


\section{Referências bibliográficas}

Aristóteles, Poética. Tradução, Prefácio, Introdução, Comentário e Apêndices de Eudoro de Souza. Porto Alegre: Editora Globo, 1966.

Benjamin, Walter. “A Tarefa - Renúncia do Tradutor" (1923). Trad. de Suzana Kampff Lages. In: HeIdermanN, Werner (Org.). Antologia Bilíngüe. Clássicos da Teoria da Tradução. Volume I: Alemão-Português. Florianópolis: UFSC, Núcleo de Tradução, 2001.

Berman, Antoine. A Prova do Estrangeiro. Cultura e Tradução na Alemanha Romântica. Trad. de Maria Emília Pereira Chanut. Bauru: EdUSC, 2002. Boyle, A. J (ed.). Roman Epic. London: Routledge, 1997.

CAMPOS, Haroldo de. Metalinguagem e Outras Metas. São Paulo: Cultrix, 1992. . "Odorico Mendes: Patriarca da Transcriação". In HoMEro, Odisséia. São Paulo: Edusp /Ars Poética, 1992, pp.11-18.

Chociay, Rogério. Teoria do Verso. São Paulo: McGraw-Hill do Brasil, 1974.

Crusius, Federico. Iniciación en la Métrica Latina. Versão e adaptação de Ángeles Roda. Barcelona: Bosch Casa Editorial, 1951.

GRAMACHO, Jair. "Introdução", in Hinos Homéricos. Brasília: Editora da UnB, 2003.

Homero. Ilíada. Trad. de Carlos Alberto Nunes. 4. ${ }^{\text {a }}$ ed., Rio de Janeiro: Ediouro, 2004.

. Odisséia. Trad. de Manuel Odorico Mendes. Edição de Antonio Medina Rodrigues. São Paulo: Edusp / Ars Poetica, 1992.

HorácIO. Arte Poética. Introdução, Tradução e Comentários de R. M. Rosado Fernandes. Lisboa: Editorial Inquérito, 1984.

MoIsés, Massaud. Dicionário de Termos Literários. 4. a ed., São Paulo: Cultrix, 1985.

Moore, Douglas. Guia de los Estilos Musicales. Trad. de José Maria Martín Triana. Madrid: Taurus Ediciones, 1981.

Nougaret, Louis. Traité de Métrique Latine Classique. Paris: Klincksieck, 1948.

Nunes, Carlos Alberto. Os Brasileidas. São Paulo: Edições Melhoramentos, 1962.

OvíDio. As Metamorfoses. Trad. de Antônio Feliciano de Castilho. Rio de Janeiro: Organização Simões Editora, 1959. . Metamorfoses. Trad. de Bocage. Introdução de João Angelo Oliva Neto. São Paulo: Hedra, 2007.

PereirA, Maria Helena da R., Estudos de História da Cultura Clássica II. Cultura Romana. 3. ${ }^{\text {a }}$ ed., Lisboa: Fundação Calouste Gulbenkian, 2002.

Piston, Walter. Harmony. $5^{\text {a. }}$ ed., New York: W. W. Norton and Company, 1987.

Predebon, Aristóteles Angheben. Edição do Manuscrito e Estudo das 'Metamorfoses' de Ovídio Traduzidas por Francisco José Freire. Dissertação de Metrado orientada por João Angelo Oliva Neto, inédita. São Paulo: USP/FFLCH/DLCV, 2007.

SCHLEIERMACHER, Friedriech. "Sobre os Diferentes Métodos de Tradução" [1813]. Trad. de Celso R. Braida. In: HeIdermanN, Werner (Org.). Antologia Bilíngüe. Clássicos da Teoria da Tradução. Volume I: 
Alemão-Português. $2^{\mathrm{a}}$ ed. Florianópolis: UFSC, Núcleo de Tradução, 2010.

TooHeY, Peter. Reading Epic. An introduction to the Ancient Narratives. New York: Routledge, 1992.

VAsconcellos, Paulo Sérgio. "A Arte de Odorico", in "Odorico Renasce", Revista Impar. São Luiz: São Luiz, 2009.

Virgílio. Eneida. Trad. de Carlos Alberto Nunes no metro original. Brasília: Editora da UnB / São Paulo: A Montanha, 1983.

. A Eneida. Trad. de Manuel Odorico Mendes. São Paulo: Atena Editora, 1956. 